\title{
Hyponatremia after anticoagulant treatment: a rare cause of adrenal failure
}

\author{
Benedetta Zampetti1, Roberto Attanasio² and Renato Cozzi1 \\ Endocrinology ${ }^{1}$ Niguarda Hospital and ${ }^{2}$ Endocrinology, Galeazzi Institute IRCCS, Milan, Italy
}

Correspondence

should be addressed

to B Zampetti

Email

benedettazampetti@yahoo.it

\section{Summary}

A 69-year-old male was admitted for severe hyponatremia disclosed after an accidental fall. He was anticoagulated from 2 months after the implantation of a biologic aortic valve prosthesis. The work-up disclosed adrenal failure and MRI showed bilateral adrenal hemorrhage. Clinical picture and lab parameters normalized quickly after the appropriate replacement treatment. Anticoagulation excess should be added to the list of drugs potentially causing hyponatremia.

\section{Learning points:}

- Hyponatremia requires a complete and timely workup in order to start an appropriate treatment for the improvement of clinical conditions.

- History is crucial: a detailed list of drugs potentially causing hyponatremia should be collected. Anticoagulants should be added to the list, mostly in the event of excessive anticoagulation.

- Intra-adrenal hemorrhage is a rare cause of hyponatremia and adrenal failure.

- The ACTH test is still the gold standard for the diagnosis of hypoadrenalism.

\section{Background}

Hyponatremia is a frequent event in elderly inpatients that requires a complete workup for the establishment of diagnosis and the start of an appropriate causal treatment (1). In the management of hyponatremia, it is of utmost importance to discriminate the time course, i.e. an acute vs chronic onset, and then to avoid two main errors: a delay in treatment and an overzealous rapid correction, causing hyponatremic encephalopathy and osmotic demyelination syndrome, respectively, both with an ominous prognosis $(2,3)$.

\section{Case presentation}

A 69-year-old male arrived in ER after an accidental fall, without losing consciousness, with head trauma and an ear wound.

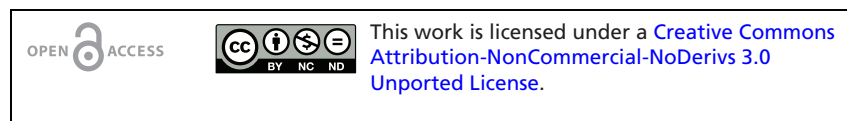

Past history was remarkable for two aspects. An MRI performed a few months before, following abdominal pain, had shown a small pancreatic lesion, which was proposed for radiologic follow-up within 6 months by the oncologist and surgeon consultants. Two months before the patient had been submitted to cardiac surgery for severe aortic stenosis. A biologic valvular prosthesis had been implanted and oral anticoagulation (OAC) had been started. Notably hyponatremia was reported at discharge (122 mM/L, nv 132-145) but no indication had been given. During the following rehabilitation period, the patient complained anorexia, fatigue, progressive weight loss and depression. Serum sodium was unchanged.

Physical examination at ER disclosed poor clinical conditions, mental confusion, pallor and arterial hypotension $(80 / 60 \mathrm{mmHg})$. 
Table 1 Changes in sodium, potassium and cortisolemia values over time.

\begin{tabular}{lcc}
\hline & $\mathbf{N a}(\mathrm{mM} / \mathrm{L})$ \\
\hline At arrival in ER & 114 \\
After hydrocortisone $100 \mathrm{mg}$ & 118 \\
At discharge & 136 \\
After 2 months & 139 \\
\hline
\end{tabular}

\begin{tabular}{c}
$\mathbf{K}(\mathrm{mM} / \mathrm{L})$ \\
\hline 6 \\
6 \\
4.5 \\
4.5
\end{tabular}

\begin{tabular}{c} 
Cortisol $(\mu \mathrm{g} / \mathrm{L})$ \\
0.6 \\
0.05 \\
\hline
\end{tabular}

\begin{tabular}{c}
\hline $\mathbf{A C T H}(\mathrm{ng} / \mathrm{L})$ \\
1297 \\
58
\end{tabular}

Lab parameters at ER disclosed (Table 1): severe hyponatremia $(114 \mathrm{mM} / \mathrm{L}, \mathrm{nv}: 132-143)$, hyperkalemia (6.05 mM/L, nv: 3.4-5.2), low-grade renal failure (serum creatinine: $1.28 \mathrm{mg} / \mathrm{dL}, \mathrm{nv}: 0.5-1.1$; urea: $60 \mathrm{mg} / \mathrm{dL}, \mathrm{nv}$ : 18-48), INR 4.5 (therapeutic target 2-3). Brain CT did not disclose any bleeding or expansive lesions, but old ischemic lesions (in the insular region bilaterally and in the subcortical posterior right area). The patient was admitted.

Hypopituitarism was hypothesized, prompting evaluation of serum cortisol at $12 \mathrm{pm}(0.6 \mu \mathrm{g} / \mathrm{L}, \mathrm{nv}$ at 07:00-10:00 h: 0.62-1.8) and FT4 (16.2ng/L, nv: 9.217). Fluid resuscitation and hydrocortisone, $100 \mathrm{mg}$ iv, were administered for persistent hypotension. The following morning, serum sodium was increased up to $118 \mathrm{mM} / \mathrm{L}(+4 \mathrm{mM} / \mathrm{L})$. Serum cortisol was again assayed at $08: 00 \mathrm{~h}(0.6 \mu \mathrm{g} / \mathrm{L})$ and the patient was referred to the endocrinology ward during the afternoon of Friday.

As FT4 and cortisol levels apparently ruled out hypopituitarism, an ACTH test was planned for the next Monday and fluid restriction was started. After $48 \mathrm{~h}$, it was unsuccessful. Abdomen MRI was performed to evaluate the known pancreatic lesion and rule out a paraneoplastic SIAD. No change was shown at the pancreatic level but hyperintense T1-weighted lesions were disclosed in both the adrenals, consistent with bleeding (Fig. 1, right adrenal size: $24 \times 10 \mathrm{~mm}$; left adrenal size: $14 \times 15 \mathrm{~mm}$ ).

Increased ACTH and renin levels were disclosed (1297 ng/L, nv: 7-63; and 309.2mU/L, nv: 2.8-39.9, in recumbent position, respectively) and the peak cortisol level after ACTH $1 \mu \mathrm{g}$ iv $(0.66 \mu \mathrm{g} / \mathrm{L}, \mathrm{nv}>1.8)$ pointed to adrenal failure.

A diagnosis of primary hypoadrenalism due to bilateral adrenal bleeding during OAC was made. The OAC was withdrawn in agreement with the cardiac surgeon because it was no longer indicated and specific treatment was started with cortisone acetate $(25+12.5 \mathrm{mg} /$ day $)$ and fludrocortisone $(0.1 \mu \mathrm{g} /$ day $)$. A marked quick clinical improvement was observed (appetite, blood pressure, well-being), with electrolyte normalization within a week.

At the 2-month follow-up, clinical conditions were satisfactory, with the complete recovery of body weight and arterial pressure $(120 / 80 \mathrm{mmHg})$, as well as electrolytes
(Na: $136 \mathrm{mM} / \mathrm{L}, \mathrm{K}: 4.5 \mathrm{mM} / \mathrm{L}$ ). Replacement treatment was confirmed with cortisone acetate (progressively reduced to $18.75 \mathrm{mg} /$ day administered in three doses) and fludrocortisone $(0.1 \mu \mathrm{g} / \mathrm{day})$.

ACTH test after 6 months showed the worsening of hypoadrenalism (peak cortisol levels: $0.05 \mu \mathrm{g} / \mathrm{L}$ ).

\section{Discussion}

Hyponatremia is a frequent and underestimated event in elderly patients admitted to ER (1). It induces clinical pictures that are often puzzling, attributed to depression or degenerative vascular brain alterations. It is thus essential to draw a comprehensive diagnostic framework that is a prerequisite for the set up of an appropriate treatment capable of improving dramatically the clinical picture (2). The combination of hyponatremia and hyperkaliemia as in this case, should point strongly to hypoadrenalism. Physicians taking care of the patient at first were diverted towards alternative diagnoses, such as hypopituitarism and SIAD (the latter due to the known undiagnosed pancreatic lesion). Both should have been considered in a lower position in the ranking order of probability and were eventually ruled out.

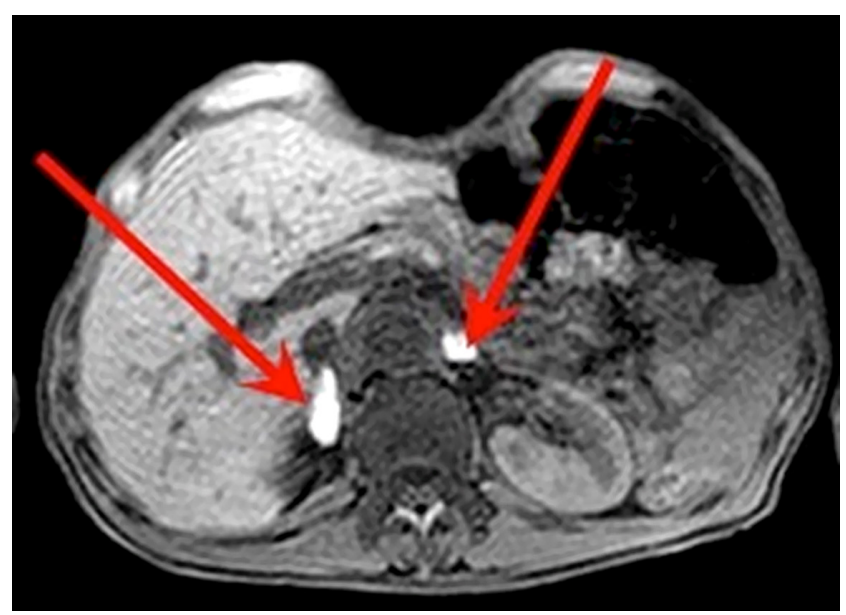

Figure 1

Hyperintense T1-weighted lesions disclosed in both the adrenals, consistent with bleeding, disclosed by abdomen MRI. 
This case report shows that OAC (or better its excess, causing intra-adrenal bleeding) should be added to the known causes of hyponatremia in the elderly, sometimes concomitantly present, such as drugs (anti-depressant, carbamazepine, diuretics, ACE-inhibitors, desmopressin, cyclophosphamide, carbamazepine, phenothiazines), low-sodium diet, excessive water intake and endocrine diseases (hypothyroidism and hypoadrenalism).

At variance with other iatrogenic causes of hyponatremia, bilateral adrenal hemorrhage, which is a well-known cause of adrenal failure, is irreversible $(4,5,6,7,8,9)$. The vascular anatomy of the adrenal gland, with a plexus of many arterioles and venules, draining into a single large vein susceptible to outflow obstruction, is believed to make the gland particularly prone to hemorrhagic infarction after central vein thrombosis. Thrombosis is a frequent cause of bleeding in cases of antiphospholipid antibody and heparininduced thrombocytopenia. Rarely, bilateral bleeding occurs only in the setting of anticoagulation, with or without underlying adrenal masses. Adrenal insufficiency becomes clinically relevant when approximately $90 \%$ of the adrenal cortex has been destroyed. The repetition of the dynamic test to evaluate cortisol response to ACTH administration could thus be viewed as redundant in such a case. Furthermore, it is important to stress that $\mathrm{OAC}$ in our patient was no longer indicated and its withdrawal should not be regarded as the rule after adrenal bleeding.

We want to underline that hypoadrenalism is not ruled out by apparently normal cortisol levels (as the misleading value found at midnight in this patient and causing a delay in the diagnosis) during a powerful stress such as that experienced in the course of an acute disease. It is essential to maintain a high index of suspicion and to perform an evaluation of the entire pituitary-adrenal axis. The additional assay of ACTH levels can add useful information. The ACTH test that is still the gold standard for the diagnosis of hypoadrenalism is warranted whenever cortisol levels are in a grey area, requiring thus a more sophisticated diagnostic approach. On the contrary, it should be regarded as ancillary if morning cortisol level is very low. The error to avoid is to postpone the start of a life-saving glucocorticoid treatment until the test has been performed (or even worse to wait for its results).
Declaration of interest

The authors declare that there is no conflict of interest that could be perceived as prejudicing the impartiality of the research reported.

\section{Funding}

This research did not receive any specific grant from any funding agency in the public, commercial or not-for-profit sector.

\section{Patient consent}

Written informed consent has been obtained from the patient for publication of the submitted article. Authors must also provide a signed copy of our consent form.

\section{Author contribution statement}

$B \mathrm{Z}$ and $\mathrm{R} C$ were the physicians taking care of the patient, R A wrote the paper.

\section{References}

1 Spasovski G, Vanholder R, Allolio B, Annane D, Ball S, Bichet D, Decaux G, Fenske W, Hoorn EJ, Ichai C, et al. Clinical practice guideline on diagnosis and treatment of hyponatraemia. European Journal of Endocrinology 2014170 G1-G47. (https://doi.org/10.1530/EJE-13-1020)

2 Filippatos TD, Liamis G, Christopoulou F \& Elisaf MS. Ten common pitfalls in the evaluation of patients with hyponatremia. European Journal of Internal Medicine 201629 22-25. (https://doi.org/10.1016/j. ejim.2015.11.022)

3 King JD \& Rosner MH. Osmotic demyelination syndrome. American Journal of the Medical Sciences 2010339 561-567. (https://doi. org/10.1097/MAJ.0b013e3181d3cd78)

4 Seow CJ \& Chen AW. Unusual cause of adrenal insufficiency. American Journal of Medicine 2016129 e177-e179. (https://doi. org/10.1016/j.amjmed.2016.04.014)

5 Bornstein SR, Allolio B, Arlt W, Barthel A, Don-Wauchope A, Hammer GD, Husebye ES, Merke DP, Murad MH, Stratakis CA, et al. Diagnosis and treatment of primary adrenal insufficiency: an Endocrine Society Clinical Practice Guideline. Journal of Clinical Endocrinology and Metabolism 2016101 364-389. (https://doi. org/10.1210/jc.2015-1710)

6 Comuth W, Christiansen JJ, Bloch-Münster AM \& Husted S. Bilateral adrenal gland hemorrhage in a patient treated with rivaroxaban. Blood Coagulation and Fibrinolysis 201728 102-104. (https://doi. org/10.1097/MBC.0000000000000541)

7 McGowan-Smyth S. Bilateral adrenal haemorrhage leading to adrenal crisis. BMJ Case Reports 201426 2014. (https://doi.org/10.1136/bcr2014-204225)

8 Best M, Palmer K, Jones QC \& Wathen CG. Acute adrenal failure following anticoagulation with dabigatran after hip replacement and thrombolysis for massive pulmonary embolism. BMJ Case Reports 201311 2013. (https://doi.org/10.1136/bcr-2012-007334)

9 Saleem N, Khan M, Parveen S \& Balavenkatraman A. Bilateral adrenal haemorrhage: a cause of haemodynamic collapse in heparin-induced thrombocytopaenia. BMJ Case Reports 201610 2016. (https://doi. org/10.1136/bcr-2016-214679)

Received in final form 30 July 2018

Accepted 14 August 2018 